\title{
O desenvolvimento de arranjos produtivos locais no Rio Grande do Sul: planejamento e diretrizes
}

\author{
Local productive arrangement development in Rio Grande do Sul: planning and guidelines
}

\author{
Carlos Eduardo Ruschel Anes \\ Cidonea Machado Deponti \\ Silvio Cezar Arend
}

Universidade de Santa Cruz do Sul - Unisc - Santa Cruz do Sul - Rio Grande do Sul - Brasil

\begin{abstract}
Resumo: Os Arranjos Produtivos Locais (APLs) tem sido nos últimos anos tema de políticas públicas no Brasil e em diferentes Estados da federação. Algumas referências apresentam as origens do conceito de APL e sua aplicabilidade em diferentes segmentos produtivos da economia. A necessidade de maiores estudos sobre a maneira como está sendo planejado o desenvolvimento de Arranjos Produtivos Locais parece ser importante. Nesse sentido o propósito deste artigo é analisar o Termo de Referência para o Plano de Desenvolvimento de Arranjos Produtivos Locais (APLs) no Rio Grande do Sul com as diretrizes do Planejamento Estratégico Situacional (PES). Na base teórica são abordados os direcionadores para elaboração do plano de desenvolvimento dos Arranjos Produtivos Locais no Rio Grande do Sul e o conceito de Planejamento Estratégico Situacional. A pesquisa é caracterizada como uma pesquisa explicativa e qualitativa, baseada no método bibliográfico. A interpretação dos dados baseou-se numa análise da literatura, a partir de fontes secundárias coletadas em bibliotecas, repositórios e bases de dados acadêmicas disponibilizadas. A partir das relações e discussões teóricas sugere-se que o atual instrumento de referência para elaboração de plano de desenvolvimento de arranjo produtivo local do Rio Grande do Sul possa agregar o próprio conceito de "arranjo produtivo local" diferenciando dos conceitos de "cadeias produtivas" e adequar seus termos conceituais de acordo com o Planejamento Estratégico Situacional - PES.
\end{abstract}

Palavras-chave: Política de desenvolvimento. Planejamento Estratégico Situacional. Arranjos Produtivos Locais.

\begin{abstract}
In the past years, the Local Productive Arrangements (LPA) have been theme of public politics in Brazil and in different states of the federation. Some references present the origins of the LPA concept and its applicability on different productive segments of economy. The necessity of deeper studies on how the development of Local Productive Arrangements is been planned seems important. In this sense, the purpose of this article is to analyze the Term of Reference for the Development of Local Productive Arrangements (LPA) in Rio Grande do Sul with the guidelines of Situational Strategic Planning (SSP). In the theoretical basis the directors to elaboration of the development of Local Productive Arrangements in Rio Grande do Sul and the Situational Strategic Planning concept are approached. The research is characterized as explanatory and quantitative, based in the bibliographical method. The data interpretation was based on analysis of the literature, secondary sources collected in libraries, repositories and academic data bases. After relations and theoretical discussions, it is possible to affirm that the current reference instrument to elaboration of development plan of local productive arrangements in Rio Grande do Sul can add its own concept of "local productive arrangement", differentiating from the concepts of "productive chains" and adapt its conceptual terms according to Situational Strategic Planning (SSP).
\end{abstract}

Keywords: Development Politics. Situational Strategic Planning. Local Productive Arrangements Development policy. 


\section{Introdução}

A preocupação com o desenvolvimento regional nos dias de hoje é evidenciada por várias políticas e programas de desenvolvimento direcionados para diversos setores da economia. Nesse sentido, estudos voltados para auxiliar as regiões utilizando uma base teórica adequada podem servir de apoio para elaboração de diretrizes para políticas públicas de promoção do desenvolvimento.

Um conceito que vem ganhando importância nos últimos anos e que faz parte de vários programas de desenvolvimento regional é o de Arranjo Produtivo Local (APL), que surge de experiências muito específicas em diferentes lugares do mundo e vem sendo utilizado como base para políticas de desenvolvimento.

A origem do conceito de arranjo produtivo local (APL) nos remete aos "distritos industriais", também denominados "distritos Marshallianos", estudados por Alfred Marshall no século XIX, na Inglaterra. A compreensão de Arranjo Produtivo Local (APL) pode se dar a partir da integração ou da organização entre pequenas e médias firmas e/ou a presença de cooperação relacionada à atividade principal do conjunto dessas firmas. Essa interação ou cooperação pode se estender até as instituições de ensino, as associações, os concorrentes, os fornecedores, os clientes e também o governo (CAMPOS, 2004).

A organização produtiva de diferentes localidades pode ser caracterizada de diferentes formas, pois dependem do ponto geográfico onde estão inseridas. A história, a evolução, a organização das instituições, os aspectos sociais e culturais justificam os diferentes desempenhos produtivos em decorrência de suas influências na estrutura produtiva, organização industrial, formas de governança, logística, associativismo e cooperação entre os agentes, formas de aprendizado e grau de disseminação do conhecimento especializado na localidade.

Ao mesmo tempo em que o conceito de APL é uma possibilidade para o desenvolvimento de diferentes espaços territoriais, não se pode deixar de considerar as diretrizes que estão sendo dadas a partir de programas de desenvolvimento de APL, os quais parecem carecer de maiores estudos relacionados à suas concepções e diretrizes organizativas.

O presente estudo não tem a pretensão de esgotar o debate nem mesmo definir o que está certo ou errado, mas analisar as referências estabelecidas pelo Governo do Estado do Rio Grande do Sul para os planos de desenvolvimento de Arranjos Produtivos Locais relacionando estes com as diretrizes do Planejamento Estratégico Situacional.

O artigo encontra-se estruturado, inicialmente, por uma revisão teórica acerca de Arranjo Produtivo Local (APL); a normativa para elaboração de Planos de Desenvolvimento de Arranjo Produtivo Local no Rio Grande do Sul e diretrizes do Planejamento Estratégico Situacional. Posteriormente, descreve-se o método e as discussões dos resultados encontrados, encerrando com as considerações finais.

\section{Arranjos produtivos locais}

Vários conceitos para explicar as organizações produtivas de um espaço territorial são utilizados. Essas distinções conceituais, segundo Suzigan et al (2004), surgem na literatura sobre a maneira como a produção é organizada e resumem-se a graus variados de desenvolvimento, de integração produtiva, de articulação e interação entre agentes e instituições locais e de capacidades sistêmicas para a inovação.

Para entender essa distinção conceitual é importante destacar o próprio conceito de "aglomerações": esse termo pode ser entendido como a proximidade espacial de agentes econômicos, sociais e políticos. A dinâmica econômica dos aglomerados decorrente das vantagens oriundas da proximidade geográfica dos seus agentes é importante à medida que há facilitação no acesso de matérias-primas, equipamentos, mão-de-obra, etc., ou seja, insumos para seu funcionamento. Nesse 
contexto micro e pequenas empresas podem aumentar suas chances de sobrevivência e crescimento, constituindo-se em importante fonte geradora de competitividade mercadológica (CASSIOLATO e LASTRES, 1999).

Os aglomerados, por sua vez, se materializam por meio de diferentes tipos, como os distritos industriais, os clusters, as cadeias produtivas e os arranjos produtivos locais. Segundo Cassiolato e Lastres (1999), em cada aglomerado diferentes atores podem estar envolvidos, bem como suas interações podem ser diferenciadas e, dependendo dessa interação no espaço onde estão inseridos, um ator pode fazer parte, simultaneamente, de um distrito industrial e de uma cadeia produtiva.

O distrito industrial, segundo Becattini (1999), possui sua base nos estudos de Marshall sobre a organização industrial na Inglaterra. A partir desses estudos o distrito industrial passou a ser entendido como uma entidade socioterritorial que congrega uma comunidade de pessoas e instituições em determinado espaço geográfico e histórico. Esse aglomerado congrega várias empresas, com elevado grau de especialização e interdependência, seja de caráter horizontal ou vertical.

Os clusters são também vistos como aglomerado produtivo. Suas características vão ao encontro de um conjunto de empresas que apresentam naturezas produtivas similares. Em alguns casos esse tipo de aglomeração dá mais ênfase ao aspecto concorrencial em detrimento do aspecto cooperativo, como fator preponderante na dinâmica interativa entre as empresas participantes. O foco direciona-se para as empresas e não em outros atores, como instituições de ensino, pesquisa e desenvolvimento, suporte técnico, fomento, esfera pública, etc. (CASSIOLATO e LASTRES, 1999).

Outro aglomerado que se manifesta em muitas regiões consideradas produtoras é a "cadeia produtiva". Para Cassiolato e Lastres (1999) seu entendimento se dá a partir do encadeamento de empresas organizadas num processo consecutivo pelas quais insumos são movimentados e transformados por meio de num ciclo de produção, distribuição e comercialização de bens e serviços. A divisão do trabalho fica evidente à medida que cada nó (empresa) participante da cadeia é responsável por uma etapa do processo de transformação e/ou movimentação de produto ou serviços. Além disso, nesse aglomerado, não há a necessidade das empresas participantes estarem numa mesma região ou localidade.

O conceito de Arranjos Produtivos Locais (APL) surge a partir de diferentes experiências. Ao longo do tempo o conceito foi se transformando e passou a indicar também experiências em vários lugares do mundo. Ele se espalhou pelo mundo como um referencial para o desenvolvimento de políticas públicas, sendo assim necessário encontrar experiências que pudessem ser caracterizadas como APL ou no mínimo como APL potencial.

Este aglomerado procura congregar agentes econômicos, políticos e sociais em um espaço territorial. Seu foco está em um conjunto específico de atividades econômicas, que apresentam relações diretas ou mesmo incipientes. Há nessa aglomeração uma interação e uma participação de empresas, desde produtoras de bens e serviços finais até fornecedoras de insumos e máquinas, prestadoras de serviços, comércio, clientes, etc. e suas diferentes formas de associação, cooperação e representação. As organizações públicas e privadas voltadas para a formação e capacitação de recursos humanos, como escolas técnicas e universidades, instituições de pesquisa, desenvolvimento e engenharia e instituições de política, promoção e fomento também fazem parte como atores importantes para o arranjo. $\mathrm{Na}$ esteira do conceito de APL surge o termo "Sistema Produtivo Local", que passa a ser entendido como um arranjo produtivo em que os vínculos passam a serem mais consistentes e com capacidade de gerar e propagar o caráter inovador endógeno da competitividade e do desenvolvimento local (CASSIOLATO e LASTRES, 1999).

O que se percebe, com base na literatura pesquisada, é que a definição de APL está sendo abordada como uma concentração geográfica de empresas e instituições que se relacionam em 
determinados setores produtivos e serviços. Apesar de existirem concepções divergentes sobre o que sejam APLs, há convergência sobre o entendimento que os APLs sejam aglomerações de empresas que podem se organizar e interagir em diferentes setores produtivos e de serviços.

Do ponto de vista econômico Igliori (2001, p. 29) afirma que "a formação de APLs contribui para uma elevação da capacidade produtiva e competitiva das firmas, além de contribuir para uma redução nos custos, ou seja, a obtenção local de economias de escala".

Outro elemento que evidencia os APLs é a facilitação no processo de transferência e acumulação de conhecimento entre as firmas locais. E essas informações disseminadas passam a qualificar o processo decisorial de investimentos, tanto no aumento da visão de novas oportunidades de mercado e novos produtos, como também em novos processos produtivos. Contribui ainda para a redução de custos nas transferências de informações em decorrência da proximidade geográfica das firmas envolvidas (MATOS, 2004).

A proximidade física e tecnológica entre as firmas favorece o processo de inovação produtiva. Além disso, as informações podem ocorrer de maneira formal (parcerias formalizadas, contratualizadas) e de maneira informal (reuniões entre trabalhadores/empreendedores). Essas oportunidades contribuem para uma dinâmica socioeconômica mais equilibrada e equitativa.

\section{Diretrizes para o Plano de Desenvolvimento de} Arranjos Produtivos Locais no Rio Grande do Sul

Para estabelecer as diretrizes para elaboração do Plano de Desenvolvimento dos Arranjos Produtivos Locais no Rio Grande do Sul o Governo do Estado, por meio da Agência Gaúcha de Desenvolvimento e Promoção do Investimento (AGDI), utiliza-se de um Termo de Referência para auxiliar as diversas instituições que ocupam papel de governança.
Segundo a AGDI (2013, p. 01),

a construção de um Plano de Desenvolvimento para os Arranjos Produtivos Locais visa identificar as externalidades econômicas que possam ser geradas e absorvidas pelos agentes que o compõe; para tanto, a construção do Plano deverá seguir uma metodologia com enfoque participativo e estratégico. Isto significa que as organizações do APL e a comunidade devem tomar parte, com efetivo envolvimento, no processo de elaboração do Plano; mais ainda, a ideia é a de que a efetiva participação dos atores locais resulte no fortalecimento de todos os elos da cadeia produtiva presentes no $A P L$, resultando em um Plano em que empresas, entidades e a comunidade se sintam representadas e protagonistas.

A participação, mobilização e conjugação de esforços dos entes envolvidos em cada local é uma das principais premissas apontadas para a elaboração de um plano de desenvolvimento de arranjos produtivos locais. Nesse sentido o objetivo desejado é o de criar uma visão de futuro convergente das empresas, instituições não governamentais locais, da comunidade e dos poderes públicos municipal, estadual e federal, de modo a oportunizar o desenvolvimento econômico regional com equidade e sustentabilidade.

Para a AGDI (2013), a elaboração do plano deve utilizar uma metodologia participativa, estabelecendo uma agenda de ações de curto, médio e longo prazo. E para isso é necessária a caracterização da situação atual do arranjo produtivo local; a análise dos entraves e potenciais de crescimento e a definição das estratégicas para curto, médio e longo prazo.

Como metodologia para elaboração do plano, a primeira etapa pode ser entendida como um diagnóstico atual do APL. Nessa etapa é necessária a definição da técnica de coleta e de análise de dados, da relação das fontes de consulta que serão utilizadas e do plano de trabalho e cronograma físico; a identificação dos principais agentes que irão participar da elaboração do Plano de Desenvolvimento e instituições chave que irão compor a governança; a definição da agenda de reuniões com identificação dos participantes e um 
esboço da estrutura do plano para cumprimento da referida etapa do plano.

$\mathrm{Na}$ segunda etapa do plano de desenvolvimento é necessário realizar a caracterização do arranjo produtivo local (APL). Essa etapa está dividida em: contextualização do Arranjo; governança e cooperação; desenvolvimento de tecnologia e inovações; desenvolvimento sustentável; formação profissional e possibilidade local de capacitação; projetos atuais de investimento e fontes de financiamento; infraestrutura e logística; níveis atuais de qualidade e controle do processo produtivo; mapeamento da cadeia produtiva e da cadeia de valor do APL e o canal de distribuição atual para os mercados interno e externo. No quadro 01 são detalhadas todas as diretrizes para a elaboração da caracterização do arranjo produtivo.

Quadro 1 - Diretrizes para a caracterização do Arranjo Produtivo Local

\begin{abstract}
1.Contextualização:
São propostas questões de cunho histórico-cultural, quantitativo de dimensão territorial-setorial, cadastro das empresas participantes, classificação econômica, produtos produzidos, pessoas empregadas da localidade e de fora da localidade, valor da exportação e percentual do que é produzido, programas/políticas públicas específicas ou que se relacionam com os APLs.

3.Desenvolvimento de tecnologia e inovações:

Processos de gestão e de produção utilizados pelas empresas do APL; bens de capital das empresas do APL; origem das inovações técnicas da empresa; fontes de informação para inovação de processo; inovações chave em processos (produção, gestão e comercialização) e produtos, introduzidos no APL nos últimos anos; oferta local de consultoria tecnológica e serviços; número de patentes registradas decorrente da parceria entre Instituições de Ensino Superior e o APL; número de pesquisadores do meio acadêmico atuando com inovação de produtos e processos no âmbito do APL; número de projetos tecnológicos entre o meio acadêmico e Instituições de Pesquisa Tecnológica e o APL.
\end{abstract}

5.Formação Profissional e possibilidade local de

\section{Capacitação:}

Perfil educacional dos trabalhadores do APL; mercado de trabalho; existência de Instituições que ofertam capacitação para mão de obra ao arranjo; demandas atual e futura do APL para capacitação por área de conhecimento; número de publicações científicotecnológicas decorrentes da parceria entre Instituições de Ensino Superior e o APL; programas de atenção à saúde do trabalhador.

\section{Infraestrutura e Logística:}

Análise dos modais existentes para despacho/recebimento de mercadorias; alternativas para transporte de pessoas; existência e dimensão de sistemas de armazenagem.

\section{Mapeamento da Cadeia Produtiva e da Cadeia de} Valor do APL:

Capacidade instalada (ou área de produção) e respectiva utilização; fornecedores; terceirização; localização das firmas para as quais as fases da produção são terceirizadas; produção; grau de adensamento da cadeia produtiva; mapear a cadeia produtiva, identificando segmentos presentes localmente e fora do arranjo; posicionamento do APL dentro da cadeia de valor.

\section{Governança e Cooperação:}

Mapeamento das instituições que compõem a

governança; tipos de interação e cooperação entre as empresas do arranjo; ações coletivas realizadas e em andamento.

\section{Desenvolvimento Sustentável:}

Oferta de aterros para resíduos do APL; diagnóstico da situação dos resíduos sólidos e líquidos gerados nas empresas dos APLs; diagnóstico da situação da emissão de gases gerados nas empresas dos APLs; compromisso com a melhoria da qualidade ambiental; educação e conscientização ambiental; grau do impacto das empresas na comunidade de entorno.

\section{Projetos atuais de Investimento e Fontes de} Financiamento:

Atuais áreas de investimento das empresas do APL; áreas futuras que as empresas do APL tencionam investir nos próximos 5 anos; demanda potencial em termos de tipo de crédito a ser ofertado (capital de giro, financiamento de máquinas, ampliação da produção, etc.) e volume.

\section{Níveis atuais de Qualidade e Controle do Processo Produtivo:}

Certificações e selos de qualidade das empresas do arranjo; certificações nacionais e internacionais de proteção ambiental; prazo de entrega de produtos.

10.Canais de Distribuição atuais para os Mercados Interno e Externo:

Faturamento por ano, por mercado - volume e valor evolução dos últimos 5 anos e tendências; segmentos de mercado das empresas do APL; diversificação de produtos ofertados; perfil de distribuição do produto; marca do APL; destino das vendas do APL segundo o local (\%); mercado externo; dificuldades no atendimento ao mercado nacional e ao mercado externo; localização os principais concorrentes das empresas do APL.

Fonte: Elaborado pelos autores com base no termo de referência para elaboração dos planos de desenvolvimento de APLs no Rio Grande do Sul da AGDI (2013). 
Há ainda a exigência de validação por meio de seminário com ampla divulgação e entrega de relatório completo da caracterização do APL, sob responsabilidade da respectiva governança, para a AGDI.

$\mathrm{Na}$ sequência do processo de elaboração do plano de desenvolvimento está a necessidade de análise dos dados coletados que caracterizam os arranjos produtivos locais. Nessa etapa a AGDI (2013) por meio do seu Termo de Referência sugere a utilização da matriz SWOT/FOFA (forças e oportunidades, fraquezas e ameaças) para classificação e análise das informações. Como na etapa anterior, ao seu final deverá ser validada por meio de seminário e entregue relatório com as devidas análises para a AGDI.

As definições de estratégias e objetivos são esperadas na terceira etapa da elaboração do plano de desenvolvimento do arranjo produtivo local. Nessa etapa é necessária a formalização de uma visão compartilhada entre os atores envolvidos justificando o desenvolvimento econômico, social, ambiental e regional do APL numa perspectiva mínima de cinco anos. Essas estratégias deverão ser fragmentadas por grupos temáticos e organizadas como ações de curto, médio e longo prazo. Além disso, deverão ser estabelecidos indicadores a serem utilizados para medir cada resultado que se espera em cada ação.

Assim, o plano de desenvolvimento do arranjo produtivo local estará constituído e pronto para sua execução dentro das normas estabelecidas no Termo de Referência da Agência Gaúcha de Desenvolvimento e Investimento do Estado do Rio Grande do Sul.

\section{O Planejamento Estratégico Situacional}

O Planejamento Estratégico Situacional (PES) tem sua origem baseada no planejamento estratégico estudado na área da Administração e sua aplicabilidade está mais voltada para o setor público. O seu principal idealizador foi o estudioso chileno Carlos Matus, que apresentou como método alternativo mais democrático e participativo para diferentes esferas governamentais.

Como premissa do seu idealizador Carlos Matus o Planejamento Estratégico Situacional foi desenvolvido para ajudar na organização da máquina administrativa do governo, diferente do tradicional planejamento estratégico empresarial. Segundo Matus,

...não devemos confundir o planejamento com a predição. A predição é um recurso de cálculo utilizado pelos governantes e planejadores, mas não é o único. O planejamento situacional é semelhante a uma guerra de trincheiras contra a incerteza futura gerada pelos sistemas complexos (MATUS, 1993, p. 29).

O Planejamento Estratégico Situacional se difere do Planejamento Estratégico Empresarial por ser pautado na democracia e na descentralização e apresenta resultados da participação e criação coletiva (GONÇALVES, 2005).

A interação coletiva no processo de PES envolve conflito e/ou cooperação entre sujeitos que muitas vezes possuem objetivos convergentes e divergentes. A habilidade de articulação entre estratégia e tática nesse contexto é fundamental para alcançar objetivos em que muitas vezes necessita-se vencer resistências ou obter apoio de diferentes sujeitos.

Dois espaços são definidos no contexto de relações entre diferentes indivíduos e atores sociais, os espaços da liberdade e da igualdade. Esses espaços podem estar em confronto à medida que aqueles mais fortes se utilizarem da liberdade para produzir maior desigualdade. Nesse momento a contradição se estabelece com o espaço da igualdade.

Com base nessas contradições que podem ocorrer em diferentes contextos pode-se perceber certa distinção entre o termo "diagnóstico" utilizado em planejamentos estratégicos empresariais e "análise situacional" utilizada no planejamento estratégico situacional. Parecem de certa forma, sinônimos, mas não o são. O diagnóstico se estabelece a partir da impessoalidade, não necessitando da identificação do autor que explica. 
De certa forma ele é validado pelo seu caráter científico, pelos méritos de sua proposição, não por quem diagnostica. Já a análise situacional, em contraposição ao diagnóstico, somente valoriza uma informação prática oriunda de um ator no jogo social se ele for identificado (MATUS, 2000).

Dessa forma o diagnóstico, por seu caráter impessoal, pode desconsiderar a existência dos atores sociais e gerar planos dissonantes e sem qualquer compromisso com a ação necessária para determinado conjunto de sujeitos sociais. A análise situacional, por sua vez, procura valorizar o diálogo entre os sujeitos sociais valorizando a interação humana, tanto em contextos de cooperação ou de conflito, o que permite o conhecimento das motivações e possíveis ações dos diferentes sujeitos.

A situação é a explicação da realidade, elaborada por uma força social em função da sua ação e da sua luta com outras forças sociais. Ela se refere ao ator da explicação, seus oponentes e aliados, suas ações, às ações de seus oponentes e aliados, assim como à realidade social construída no processo social. Essa realidade apresenta-se como dada num certo momento da formação social, mas é produto da luta constante por manter, reproduzir e transformar o sistema. Esta explicação situacional é alternativa ao conceito tradicional de diagnóstico (...) (MATUS, 1993, p. 219).

Outro aspecto importante destacado por Carlos Matus é a importância do alinhamento entre estratégia e táticas dentro do planejamento situacional. A necessidade desse entendimento é fundamental, pois em diferentes ambientes de interação social os objetivos de sujeitos podem ser distintos e ao mesmo tempo estão inseridos em um mesmo planejamento, gerando uma relação de forças. Nessa relação ou se vence a resistência dos sujeitos em confronto ou se obtém uma cooperação entre eles por meio de uma situação-objetivo comum.

A presença de conflito e/ou cooperação no planejamento é inevitável (MATUS, 1993).

A compreensão do conceito de Tática e Estratégica é imprescindível para que não ocorram riscos de estarem desalinhados dentro de um planejamento. Assim, Matus (1993, p. 195) destaca que:

Tática é o uso ou aplicação de recursos escassos, visando uma mudança situacional imediata. Estratégia é o uso ou aplicação da mudança situacional visando a alcançar a situação-objetivo. Desta forma, o encadeamento de operações táticas constrói a viabilidade da estratégia. A estratégia e a tática desenvolvem-se entre oponentes historicamente situados que, por serem atores criativos, não podem enumerar exaustivamente seus planos possíveis e, conseqüentemente, tentam resolver um problema quaseestrutura.

Nesse sentido o Planejamento Estratégico Situacional idealizado por Carlos Matus e utilizado em diversos países como instrumento balizador para o desenvolvimento e aplicabilidade de políticas públicas destinadas a diferentes espaços territoriais, torna-se um instrumento importante na tentativa de valorização dos sujeitos e atores sociais numa perspectiva de intensiva interação social. Assim a possibilidade de se estabelecer políticas originadas e aplicadas para o bem social passa também ter uma perspectiva de aplicabilidade mais equilibrada entre princípios de liberdade e igualdade.

\section{A política de APLs no Rio Grande do Sul e o Planejamento Estratégico Situacional}

A partir dessa seção são descritos os componentes estabelecidos pelo Termo de Referência para elaboração de Planos de Desenvolvimento de Arranjos Produtivos Locais da Agência Gaúcha de Desenvolvimento e Promoção do Investimento (AGDI), órgão vinculado ao Governo do Estado do Rio Grande do Sul e analisados a partir dos pressupostos teóricos do Planejamento Estratégico Situacional idealizado por Carlos Matus como instrumento destinado ao planejamento e gestão pública.

A preocupação com o marco teórico utilizado para fundamentar o Termo de Referência é evidente, sua base teórica tenta interpretar as diretrizes do Planejamento Estratégico Situacional (PES) de Carlos 
Matus. A participação e o incentivo de que o plano de desenvolvimento seja construído a partir do comprometimento e participação de todos os atores de um espaço territorial/setorial fica evidenciada a partir das proposições estabelecidas no termo.

Um dos pontos que chama a atenção no termo de referência da AGDI (2013) é que no momento da classificação das estruturas produtivas ele afirma que para a elaboração do plano de desenvolvimento devem ser utilizados os conceitos de cadeia produtiva e cadeia global de valor ou cadeias de suprimento.

Por mais que o apelo para uma análise territorial, dentro de uma concepção baseada nos distritos industriais, Clusters ou a partir do produto final tenha sido citada ao longo do termo de referência, abre-se oportunidade para contribuições. A primeira, dentro dessa lógica, pode-se refletir na possibilidade de ampliação para outros conceitos, ou seja, além dos conceitos propostos de cadeia produtiva e cadeia global de valor, que, como foi abordado anteriormente neste artigo, elas se dão a partir do encadeamento de empresas organizadas num processo consecutivo pelos quais insumos são movimentados e transformados por meio de atividades de produção, distribuição e comercialização.

Nesse aglomerado em "cadeia" não há necessidade das empresas participantes estarem, geograficamente, próximas. A partir dessa constatação surge uma dissonância conceitual com os distritos industriais, que defendem proximidade espacial, ou seja, as organizações produtivas devem estar organizadas em determinada área espacial e somente é considerado o mercado externo para fins de comercialização dos seus produtos. Portanto, não há interação ou encadeamento no tocante à produção fora das fronteiras territoriais e sim, possibilidade de comercialização.

No conceito de cadeia esse aspecto não se distingue, ou seja, poderá fazer parte tanto da cadeia produtiva, de suprimentos, distribuição e comercialização qualquer empresa posicionada fora do espaço territorial. Sendo assim, as políticas públicas devem estimular e valorizar a produção regional e facilitar articulações com mercados externos no tocante a insumos e tecnologias ainda não disponíveis regionalmente. Dessa forma, do ponto de vista econômico, a balança comercial regional poderá alcançar patamares superavitários que possam contribuir auxiliando seu crescimento.

O termo de referência considera também as organizações produtivas concebidas e materializadas a partir de Clusters, em que o apelo competitivo fica evidenciado. Não se tem dúvida de que essa concepção de organização produtiva seja importante para o crescimento econômico, mas deve-se ter cuidado para que não seja o "modelo" predominante de organização produtiva, pois seu apelo e entendimento conceitual estão na competitividade em essência e não na cooperação. E quando consideramos setores da economia como os ligados a micro e pequenos empresários e às unidades rurais de produção familiares, a materialização de Clusters pode gerar a concentração de riqueza em pequenos grupos de empresários e produtores rurais reproduzindo apenas o crescimento baseado nos princípios de liberdade e não nos princípios de igualdade de oportunidade interpretados por Carlos Matus. É preciso, nessa lógica, políticas e programas baseados em conceitos de organizações produtivas que contemplem redes de cooperação entre micro e pequenos empresários e agricultores familiares. Do ponto de vista conceitual de Clusters a oportunidade de cooperação fica mais difícil.

No título do Termo de Referência para elaboração do plano de desenvolvimento aparece o termo "arranjo produtivo local". No entendimento de Cassiolato e Lastres (1999), precursores dos primeiros estudos realizados em nível de Brasil na década de 1990, o conceito de Arranjo Produtivo Local é entendido como uma aglomeração produtiva com dinâmica própria. Diferente do aglomerado em "cadeia", o conceito de Arranjo Produtivo Local concentra agentes econômicos, políticos e sociais em um espaço regional. Há nesse aglomerado uma interação e uma participação de empresas, desde produtoras de bens e serviços finais até fornecedoras de insumos e máquinas, prestadoras de serviços, 
comércio, clientes, etc. e suas diferentes formas de associação, cooperação e representação. As organizações públicas e privadas voltadas para a formação e capacitação de recursos humanos, como escolas técnicas e universidades; pesquisa, desenvolvimento e engenharia; política, promoção e fomento também fazem parte como atores importantes para o arranjo. Nesse sentido, percebese que o termo de referência poderia agregar a seu marco teórico o conceito de Arranjo Produtivo Local (APL). Dessa forma, conceitualmente falando, as concepções teóricas ficariam mais completas e dariam uma base conceitual mais sólida para o entendimento das reais intenções da política de desenvolvimento produtivo estabelecida pelo Governo do Estado do Rio Grande do Sul.

Não queremos afirmar com isso que o conceito de "cadeias" não sirva para auxiliar no desenvolvimento do Estado, mas sugerir que se inclua o conceito de Arranjo Produtivo Local para facilitar a compreensão por parte dos atores e organizações produtivas já existentes e em processo de transformação nas diversas regiões do Rio Grande do Sul.

O marco teórico utilizado como fundamentação de Planejamento Estratégico Situacional no termo de referência atende aos propósitos, objetivos e metodologia expressos ao longo do termo, com exceção do explicitado na seção 2.4 do documento de referência intitulado "Definição de Estratégias e Objetivos" quando se refere à "Identificação dos temas relevantes para o Plano a partir do diagnóstico realizado" (AGDI, 2013, p. 12). Nesse momento o termo de referência expressa certa incoerência com sua base conceitual no Planejamento Estratégico Situacional de Carlos Matus.

$\mathrm{Na}$ interpretação de Carlos Matus o "diagnóstico" é utilizado para planejamentos estratégicos empresariais e a denominação "análise situacional" para planejamentos estratégicos situacionais. Para Matus o diagnóstico se materializa de maneira impessoal, pois não necessita da identificação do autor. Além disso, ele é validado pelo seu caráter científico, não por quem diagnostica. Já a "análise situacional", em contradição à denominação "diagnóstico", somente valoriza um dado prático oriundo de um sujeito ou ator social a partir da sua identificação (MATUS, 2000).

A partir dessa diferença entre o entendimento de "diagnóstico" e "análise situacional" percebe-se que o primeiro pode desconsiderar a existência de sujeitos sociais e gerar planos incoerentes com as reais necessidades do conjunto de atores sociais de um dado arranjo produtivo. Já o conceito de "análise situacional", segundo Matus (2000), valoriza o diálogo entre os atores sociais e a interação humana, tanto em ambientes de conflitos ou de cooperação o qual facilita na obtenção das reais motivações convergentes e/ou divergentes dos sujeitos e atores envolvidos.

Neste sentido, entendemos que é fundamental a incorporação adequada do conceito de análise situacional ao Termo de Referência, posto que a discussão e construção participativa de um projeto de desenvolvimento envolvendo produtores rurais $e$ demais agentes regionais é o objetivo maior a ser alcançado para o desenvolvimento das regiões do estado do Rio Grande do Sul.

\section{Considerações finais}

O presente estudo procurou analisar as diretrizes expressas no Termo de Referência para Elaboração de Planos de Desenvolvimento de Arranjos Produtivos Locais da Agência Gaúcha de Desenvolvimento e Promoção de Investimento (AGDI) vinculada ao Governo do Estado do Rio Grande do Sul, com os conceitos teóricos de Carlos Matus a partir do Planejamento Estratégico Situacional (PES).

Um dos pontos que merece destaque é com relação ao marco teórico que fundamenta as estruturas produtivas. O termo de referência da AGDI é utilizado como base de concepção de diversos planos de desenvolvimento de Arranjos Produtivos Locais e, por ser documento importante, sugere-se que acrescente maior fundamento conceitual sobre Arranjos Produtivos Locais. Essa forma de aglomerado deveria ser expressa no próprio 
instrumento de referência, mas com base no estudo e análise realizada isso não ocorre.

Além disso, o conceito de "cadeia" é utilizado como base para caracterizar os planos de desenvolvimento de Arranjos Produtivos Locais. Dessa forma, ocasiona uma dissonância conceitual pelo fato de que "cadeia" e "arranjo produtivo local" são duas vertentes teóricas diferentes de aglomerados produtivos.

Outro elemento que é identificado na análise do Termo e se contrapõe à interpretação de Carlos Matus como idealizador do Planejamento Estratégico Situacional, aparece no momento em que o instrumento de referência cita a necessidade de um "diagnóstico" para fundamentar as estratégias e objetivos do plano. Em se tratando do entendimento conceitual o termo adequado seria "análise situacional" em lugar de "diagnóstico". Assim, o conceito passaria a estar coerente com a base teórica do Planejamento Estratégico Situacional.

Ao concluir esse estudo fica evidente a necessidade de uma revisão conceitual no instrumento utilizado como referência para elaboração de plano de desenvolvimento de arranjo produtivo local. Do ponto de vista do senso comum o instrumento apresenta diretrizes claras e objetivas, mas acredita-se que ajustes conceituais e pontuais, que foram destacados, podem contribuir ainda mais com essa importante política pública do Estado do Rio Grande do Sul.

\section{Referências}

AGDI - Agência Gaúcha de Desenvolvimento e Promoção do Investimento. Termo de Referência para elaboração de Plano de Desenvolvimento de Arranjos Produtivos Locais (APLS) do Rio Grande do Sul. Diretoria de Produção e Inovação. 2013.

BECATTINI, Giacomo. Os Distritos Industriais da Itália. Empresários e empregos nos novos territórios produtivos: o caso da terceira Itália. Rio de Janeiro: DP\&A, 1999.

CAMPOS, A., Arranjos Produtivos no Estado do Paraná: o caso do município de Cianorte, Curitiba, 2004, 218 f. Tese (Doutorado em Desenvolvimento Econômico) - Setor de Ciências Sociais Aplicadas, Universidade Federal do Paraná.
CASSIOLATO, José Eduardo, LASTRES, Helena Maria Martins. Globalização \& inovação localizada: experiências de sistemas locais no Mercosul. Brasilia: IBICT/MCT, 1999.

GONÇALVES, Raquel Garcia. Modelos Emergentes de Planejamento: Elaboração e Difusão. Um estudo do Planejamento Estratégico Situacional. Rio de Janeiro, 2005, 201 f., Tese apresentada ao Curso de Doutorado do Programa de PósGraduação em Planejamento Urbano e Regional da Universidade Federal do Rio de Janeiro UFRJ.

IGLIORI, D., Economia dos Clusters Industriais e Desenvolvimento, São Paulo: Iglu, 2001.

MATOS, M. Políticas públicas para arranjos produtivos locais: o arranjo de gemas de Teófilo Otoni - Minas Gerais, Rio de Janeiro, 2004, 121 f., Monografia (De Bacharelado na Graduação em Ciências Econômicas) - Instituto de Economia, Universidade Federal do Rio de Janeiro.

MATUS, Carlos. Política, planejamento \& governo. v.1. Brasília: IPEA, 1993

MATUS, Carlos. Teoria del juego social. Caracas: Fondo Editorial ALTADIR, 2000.

SUZIGAN, W. et al. Clusters ou Sistemas locais de produção: mapeamento, tipologia e sugestões de políticas. Revista de Economia Política, v. 24, n. 3, p. $543-562$, Jul. 2004. 